\title{
Characteristics of Indium-Tin-Oxide Nanoparticles Prepared by Controlled Chemical Coprecipitation Method
}

\author{
Hyun Woo Kim and Yeong Il Kim* \\ Department of Chemistry, Pukwong Kational Lnwersity, Busan 608-737, Korea. ${ }^{\star}$ E-mail: wimapkn ac.kr \\ Received Mav 21, 2008
}

Key Words : ITO. $\operatorname{In}_{2} \mathrm{O}_{3}$. Bixbỵite. Corundum

Sn-doped $\operatorname{In}_{2} \mathrm{O}_{3}$, usually called indium-tin-oxide (ITO). has been widely utilized in optoelectronic devices as a form of thin film due to its high electrical conductivity and transparency to visible light. ${ }^{\prime}$ Recent studies of ITO have been focused on shape and size controlled nanoparticles for the versatile device applications. ${ }^{2}$ The crystal structure of ITO nanoparticles follows that of $\mathrm{In}_{2} \mathrm{O}_{3}$ that is known to have two types of crystal structures: bixbyite structure of cubic unit cell ${ }^{\text {sa }}$ and corundum structure of rhombohedral or hexagonal unit cell. ${ }^{\hat{b} b}$ While most of pure $\mathrm{In}_{2} \mathrm{O}_{3}$ or ITO nanoparticles were fabricated as bixbyite type. not many reports of corundum type nanoparticles are known despite the corundum type ITO has some advantages such as higher specific gravity and more stable conductivity. This is just because of synthetic difficulty of the high temperature and high pressure condition. ${ }^{4}$ Recently Qian et al. reported the hydrothermal method of synthesizing ITO or $\mathrm{In}_{2} \mathrm{O}_{3}$ nanoparticles and nanowire of corundun structure in a relatively mild conduction. ${ }^{5}$ Gurlo et al. also synthesized conndum type $\mathrm{In}_{2} \mathrm{O}_{3}$ in ambient pressure condition using acetylacetone/methanol solvent condition. ${ }^{6}$ Lee et al. reported uniformly size-controlled nanocubes of corundum $\mathrm{In}_{2} \mathrm{O}_{3}$ prepared by surfactant-assisted method. ${ }^{7}$ All these recent studies revealed that corundum type $\mathrm{In}_{2} \mathrm{O}_{3}$ could be obtained through the dehydration of $\mathrm{InOOH}$. Here, we report the preparation of corundum ITO nanoparticles by the simple temperature and $\mathrm{pH}$ controlled coprecipitation in aqueous solution.

Figure I shows X-ray diffraction pattents of ITO precursors that were prepared at different $\mathrm{pHs}$ and temperatures in aqueous solution. When the precursor was prepared at $\mathrm{pH}$ 12. it consisted of mainly cubic $\operatorname{In}(\mathrm{OH})_{3}$ at $60^{\circ} \mathrm{C}$ and some unknown phases were mixed with cubic $\operatorname{In}(\mathrm{OH})_{3}$ at 0 and 30 ${ }^{\circ} \mathrm{C}$. However, when the precursor was prepared at $\mathrm{pH} 8$, it was almost anorphous at 0 and $30^{\circ} \mathrm{C}$ and showed doninantly orthorhombic $\mathrm{InOOH}$ structure at $60^{\circ} \mathrm{C}$ as shown in Figure 1(b). When these ITO precursors were annealed above $300^{\circ} \mathrm{C}$, the structural transformation occurred. As shown in Figure 2. the precursors that were prepared at $\mathrm{pH}$ 12 were transformed to bixbyite structure ITO regardless of precipitation temperature when they were annealed at 400 ${ }^{\circ} \mathrm{C}$ for 2 hours. Whereas. those prepared at $\mathrm{pH} 8$ were changed to bixbyite or coruudum type ITO at the same condition depending on the precipitation temperature: corundum for the precipitate at $60^{\circ} \mathrm{C}$. bixbyite for the precipitate at 0 and $30^{\circ} \mathrm{C}$. The XRD patterns of bixbyite ITO whose precursors were prepared at $\mathrm{pH} 8$ are much sharper and well defined than those prepared at $\mathrm{pH} 12$. The unit cell parameter $a$ that was calculated from Nelson-Riley extrapolation for the precursor prepared at $\mathrm{pH} 8$ and $0^{\circ} \mathrm{C}$ is closest to the known bulk value $(10.118 \AA)^{3 a}$ as $10.112 \AA$. The values for the other precursors were a little smaller than this. The particle sizes calculated from Debye-Scherrer equation tells that the lower precipitation temperature was, the smaller the particle size was in the case of $\mathrm{pH} 12$. On the contrary, what was prepared at lower precipitation temperature showed larger particle in the case of $\mathrm{pH} 8$. The crystallization of the precursors prepared at $\mathrm{pH} 8$ to bixbyite structure occurred
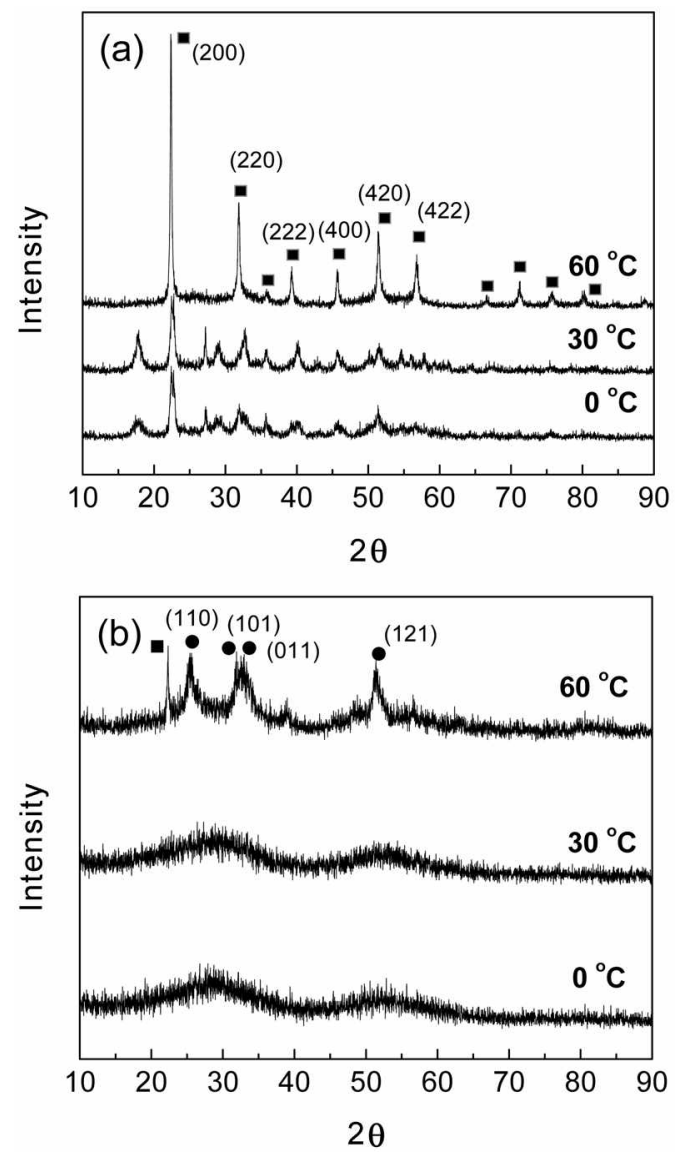

Figure 1. XRD pattenls of ITO precursors that were precipitated at various temperatures and $\mathrm{pH} 12$ (a) and 8 (b) without heat treatment. and represent XRD peaks of $\operatorname{In}(\mathrm{OH})_{3}$ and $\operatorname{InOOH}$, respectively: 

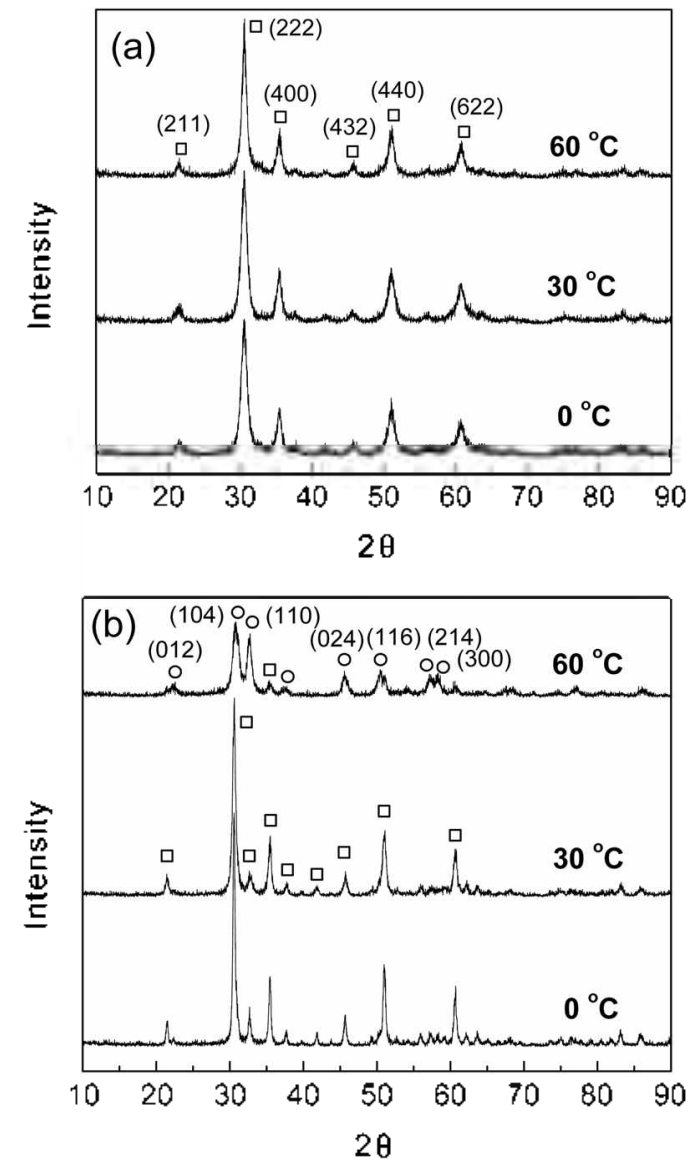

Figure 2. XRD pattems of ITO nanoparticles that were prepared by annealing of ITO precursors at $400^{\circ} \mathrm{C}$ shown in Figure 1: (a) precipitated at $\mathrm{pH} 12$ and (b) at $\mathrm{pH} 8$. Jand $\ldots$ represent XRD peaks of cubic and thombohedral $\mathrm{In}_{2} \mathrm{O}_{3}$, respectively.

from anorphous phase. while the precursors prepared at $\mathrm{pH}$ 12 were transformed nainly from cubic $\operatorname{In}(\mathrm{OH})_{3}$ to cubic $\mathrm{In}_{2} \mathrm{O}_{3}$ although some mixed phases existed in them prepared at lower temperatures. The crystallization from amorphous phase may be easier than from another crystal phase because of lower activation energy. For this reason the XRD pattems of ITO prepared at $\mathrm{pH} 8$ are much sharper than those prepared at $\mathrm{pH} 12$. The unit cell parameters of the conundum structure ITO were calculated as 5.474 and $14.522 \mathrm{~A}$ for $a$ and $c$, respectively. The a value is a little smaller and the $c$ value is a little larger than those of the known conundum $\mathrm{In}_{3} \mathrm{O}_{3}$ that were prepared at high pressure and temperature $\left(65 \mathrm{kbar} \text { and } 110^{\circ} \mathrm{C}\right)^{\text {. }}{ }^{\text {b }}$

The thermogravimetric analysis (TGA) and differential scanning calorimetric (DSC) data show clearly the difference between the precursors prepared at $\mathrm{pH} 12$ and 8 . For all three precursors prepared at $\mathrm{pH} 12$ the weight losses occurred similarly about $17 \%$ sharply until about $300^{\circ} \mathrm{C}$ as shown in Figure 3 (a). These losses are coincident to the theoretical weight loss $(16.3 \%)$ when $\ln (\mathrm{OH})_{3}$ transforms to $\ln _{2} \mathrm{O}_{3}$. DSC data show that the transformation temperatures shown as endothermic peaks in Figure 4(a) sy'stematically increased as the precipitation temperature increased. For the precursors prepared at $\mathrm{pH} 8$ the situation was more complex. The pre-
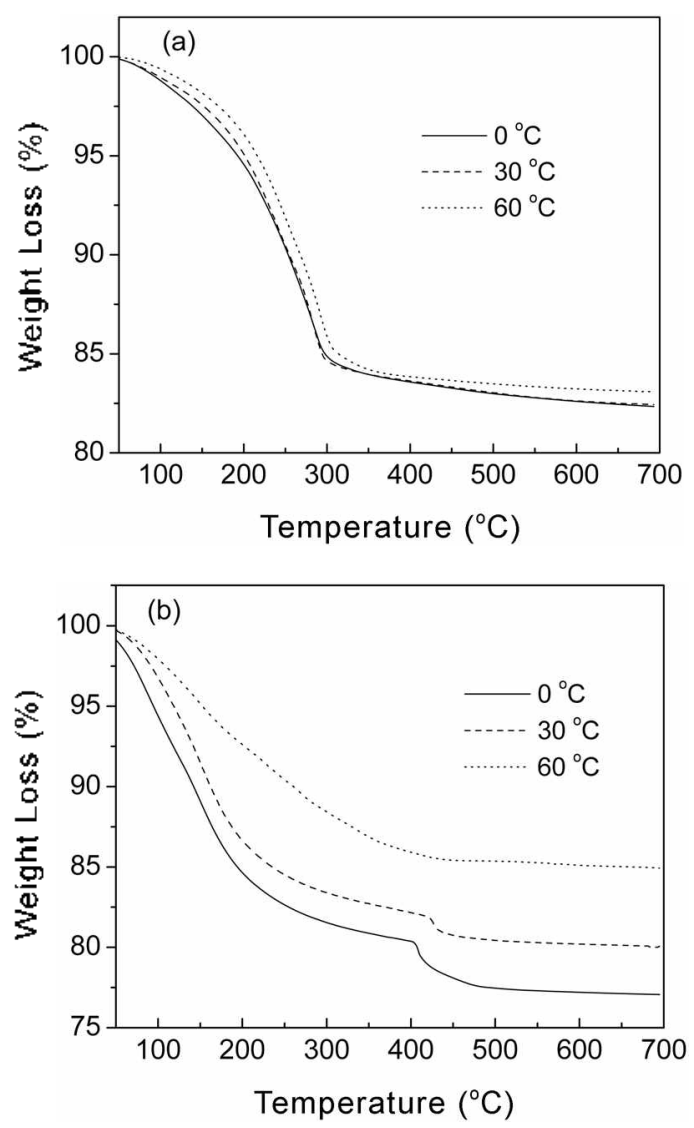

Figure 3. TGA curves of ITO precursors that were prepared at various temperatures and $\mathrm{pH} 12$ (a) and 8 (b).

cursors prepared at 0 and $30^{\circ} \mathrm{C}$ show two stages of weight losses and sharp exothermic transformations in Figure 3(b) and 4(b). The precursor prepared at lower temperature showed more weight loss. The precursors prepared at 0 and $30{ }^{\circ} \mathrm{C}$ may be in the form of metastable hydroxide hydrate. The larger weight loss than for the precursors at $\mathrm{pH} 12$ and the exothemic transformation might be explained by the dehydration from this metastable form. On the other hand. the precursor prepared at $60^{\circ} \mathrm{C}$ show one stage smooth weight loss and no sharp phase transition in the Figures. The theoretical weight loss for the transformation from $\mathrm{InOOH}$ to $\mathrm{In}_{2} \mathrm{O}_{3}$ is $6.1 \%$. In this case the loss was about $13 \%$. This discrepancy may come from the fact the precursor was hydrated in the form of $\mathrm{InOOH} \times \mathrm{H}_{2} \mathrm{O}$. And no sharp phase transition may be due to the low crystallinity as shown in its XRD data.

Figure 5 shows HR-TEM pictures and electron diffraction (ED) patterns of ITO nanoparticle samples that were prepared at $\mathrm{pH} 8$ and $0^{\circ} \mathrm{C}$ and $60^{\circ} \mathrm{C}$. The ED patterns show clearly the difference between the samples prepared at $0^{\circ} \mathrm{C}$ and $60^{\circ} \mathrm{C}$. of which crystal structure correspond to bixbyite and corwndum. respectively. The particle sizes are both about 10-20 nm and the particle morphologies in both cases are also similar from the pictures of field-emission scanning electron microscopic pictures (not shown here). The particles in both cases exhibits lattice fringes that indicate their single 

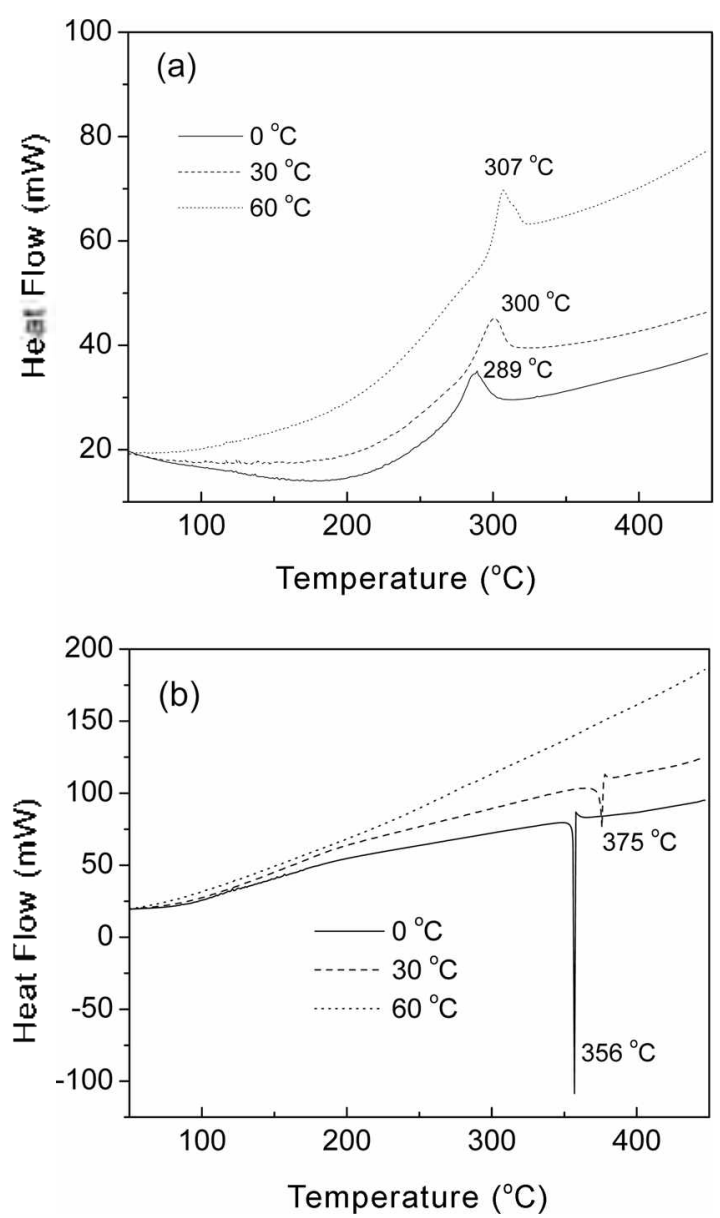

Figure 4. DSC curves of ITO precursors that were prepared at varions temperatures and $\mathrm{pH} 12$ (a) and 8 (b) (up endothemic).

crystal nature. The lattice plane distances approximately corresponds to the (222) and (104) planes for bixbyite and corundum structures. respectively.

In this study we have demonstrated that the crystal structure of ITO nanoparticles could be controlled by the precipitation condition of the precursors that were prepared by simple coprecipitation in aqueous solution. At $\mathrm{pH} 12$ the precursors were crystallized as cubic $\operatorname{In}(\mathrm{OH})_{3}$ structure regardless of precipitation temperatures herein studied and the subsequent annealing of the precursors above $300^{\circ} \mathrm{C}$ gave only cubic bixby ite ITO. However, when the precursor was prepared at $\mathrm{pH} 8$. it was amorphous or of orthorhombic InOOH structure depending on precipitation temperature. The only orthorhombic InOOH precursor that was prepared at $60{ }^{\circ} \mathrm{C}$ resulted in conndum structure of ITO. while the others gave the cubic bixbyite ITO structure. The result shows clear evidence that only rhombohedral InOOH can be transformed to the corundum structure. While cubic and amorphous $\operatorname{In}(\mathrm{OH})_{3}$ give rise to bixbyite structure after dehydration.

\section{Experimental}

Synthesis of ITO nanoparticles. The mixture solution of
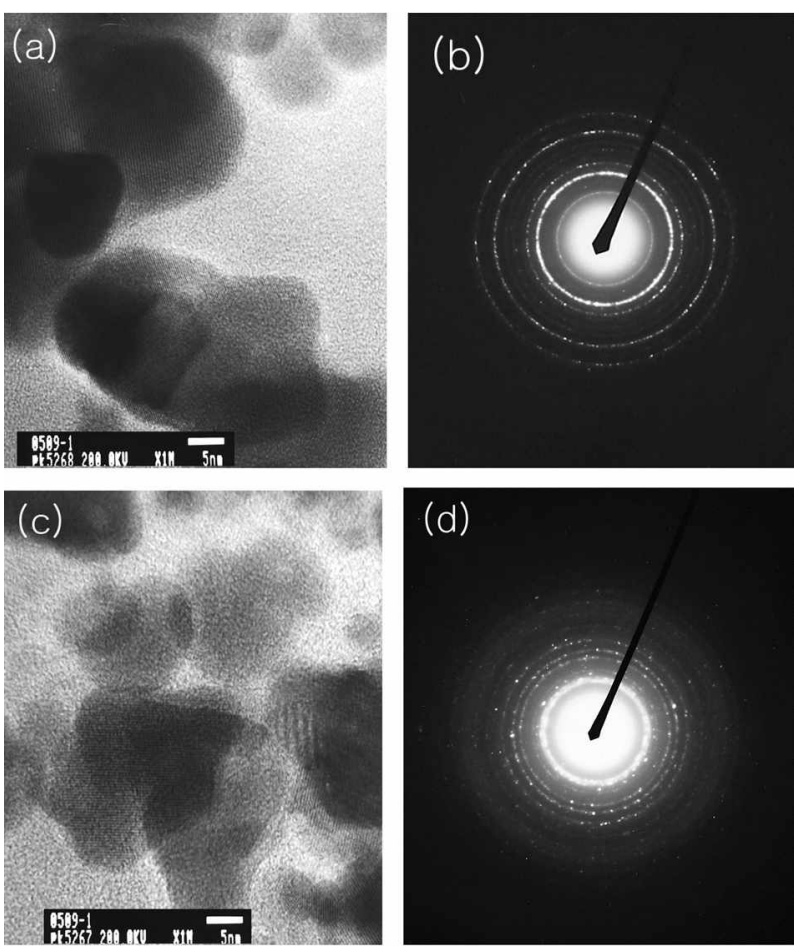

Figure 5. HR-TEM pictures and electron diftraction patterns of ITO nanoparticles that were prepared at $\mathrm{pH} 8$ and $0^{\circ} \mathrm{C}(\mathrm{C}, \mathrm{b})$ and $60^{\circ}$ "C (c, d).

$0.018 \mathrm{~mol} \operatorname{In}\left(\mathrm{NO}_{3}\right)_{3} \cdot 5 \mathrm{H}_{2} \mathrm{O}(99.9 \%$. Aldrich) and $0.002 \mathrm{~mol}$ $\mathrm{SnCl}_{4} \cdot 5 \mathrm{H}_{2} \mathrm{O}(98 \%$. Aldrich) in $50 \mathrm{~mL}$ of $0.4 \mathrm{M} \mathrm{HCl}$ was slowly introduced drop-by-drop into $300 \mathrm{~mL}$ of $1.5 \mathrm{M}$ $\mathrm{NaOH}$ solution that was previously adjusted to appropriate $\mathrm{pH}$ with conc. $\mathrm{HCl}$. During the addition of the mixed solution, the solution of $1.5 \mathrm{M} \mathrm{NaOH}$ was simultaneously added to keep an appropriate $\mathrm{pH}$. The temperature of the reaction solution was maintained constant within $\pm 1^{\circ} \mathrm{C}$ with a circulating thermostatic bath and water-jakected reaction vessel and the solution was vigorously stirred. The white precipitates appeared immediately with dropping of the mixed solution and the reaction solution was kept stirred for 1 hour after all mixture solution was added. The precipitates were centrifuged at $12.000 \mathrm{rpm}$ for 10 minutes and washed with deionized water. The centrifugation and washing were repeated 5-8 times until the washed water was free from $\mathrm{Cl}^{-}$ and $\mathrm{NO}_{3}{ }^{-}$ions. The washed precipitates were dried under vacuum at an ambient temperature. The dried and aggregated precipitates were ground in agate mortar and calcined for 2 hours at various temperatures in air.

Apparatus. XRD patterns were obtained with Phillips X'Pert-MPD X-ray diffractometer with $\mathrm{CuK} \alpha$ and $0.02 \%$ sec scan rate. Thermal analysis data were measured with Perkin-Elmer Pyris $1 \mathrm{DSC}$ and TGA 7 with $10^{\circ} \mathrm{C} / \mathrm{min}$ scan rate under $\mathrm{N}_{2}$ atmosphere. FE-SEM and TEM pictures were taken with Hitachi $\mathrm{H} 7500$ and Jeol JEM-2010, respectively

Acknowledgments. This work was supported by 2005 research year fund of Puky'ong National University. 


\section{References}

1. (a) Hartnagel. H. L.: Dawar. A. L.: Jain. A. K.: Jagdish. C. Semiconducting Transpanent Thin Films: IOP Publishing: Bristol and Philadelphia. 1995. (b) Kim, Y.-I: Yoon, I.-B.: Choy, J.-H.: Campet G. Camin. D.: Portier. I.: Salardenne, I. Bull Korean Chem. Soc. 1998. 19. 107. (c) Lee. S. H.: Lee. J. H.: Kim. K. H. Jun. J. H. Bull. Korean Chem. Soc 1989. 10.418.

2. (a) Kim. D. W.: Oh. S.-G.: Lee. J.-D. Lantmuir 1999. 15. 1599. (b) Kim, K. Y.: Park S. B. Mater Chem. Phns. 2004, 86. 210. (c) Song, I. E.: Lee. D. K.: Kin. H. W: Kim. Y. I: Kang, Y. S. Colloids Surf A 2005, 257-258. 539. (d) Wang. C.: Chen. D.: Jiao,
X: Chen. C. J. Phus Chem. C 2007. H1. 13398.

3. (a) ICPDS No. 06-0416. (b) ICPDS No. 22-0336.

4. Prewitt. C. T.: Shannon. R. D.: Rogers. D. B.: Sleight. A. W Inorg. Chem 1969,8,1985.

5. (a) Yu. D.: Wang. D.: Lu. J.: Qian. Y. Inong Chem. Comm. 2002. 5. 475. (b) Yu, D.: Yu. S.-H.: Ahang. S.; Zuo, J.; Wang, D.; Qian. Y. Ach: Fumet. Hatet 2003. 13.497. (c) Yu. D.: Wang. D.: Qian. Y. J. Solid State Chem. 2004. 177. 1230.

6. Epifani. M.: Sicillanı. P.: Gurlo. A.: Barsanı. N.: Weimar. U. $J$. Am. Chem. Soc. 2004, 126.4078.

7. Lee. C. H.: Kim, M: Kim, T.: Kim, A.; Paek. J.: Lee, J. W.; Choi. S.Y: Kim, K.; Park. J.-B.; Lee, K. J.Am. Chem. Soc. 2006, 128.9326. 